\title{
Annual Radiation Discomfort: A new climate-based framework for modeling short-wave solar radiation in indoor spaces
}

\author{
Andrea Zani ${ }^{1,4}$, Henry D. Richardson ${ }^{2}$, Alberto Tono ${ }^{3}$, Stefano Schiavon ${ }^{4}$, Edward Arens ${ }^{4}$ \\ ${ }^{1}$ Eckersley O’Callaghan Engineers, San Francisco, CA, USA \\ ${ }^{2}$ WattTime, Oakland, CA, USA \\ ${ }^{3} \mathrm{HOK}$, San Francisco, CA, USA \\ ${ }^{4}$ Center of the Built Environment, University of California, Berkeley, CA, USA
}

\begin{abstract}
Controlling the incoming solar radiation is one of the main responsibilities of sustainable building designers, in order to minimize glare and cooling loads and maximize thermal comfort and usable daylight. However most solar shading design neglects or underestimates the direct impact of indoor sunlight on occupant thermal comfort. In an effort to make the thermal impacts of transmitted solar radiation more accessible to designers, this research presents a new climate-based annual framework for the calculation of the hourly effective radiant field (ERF), and delta mean radiant temperature $(\triangle \mathrm{MRT})$ across indoor spaces with complex geometries and façade types. It also proposes a new "Annual Radiation Discomfort" (ARD) metric for comprehensively assessing the effect of solar radiation on comfort throughout a space.
\end{abstract}

\section{Introduction}

Large expanses of glass have become ubiquitous in modern design and are often rationalized as maximizing daylight and outdoor view and $40 \%$ of building occupants express dissatisfaction with the thermal environment (Karmann et al. 2018). In buildings characterized by high window-to-wall ratios (WWR), the critical design concerns about thermal comfort shift from the core to the daylit perimeter zone (Konis \& Selkowitz, 2017), due to the effects of incoming solar radiation on the occupants. Incoming solar radiation, in the form of direct, diffuse and indoor-reflected components, is responsible for many things including solar heat gains absorbed by indoor surfaces that must be removed, localized temperature rises in sunlit areas at the subzone level that challenge HVAC system design and overcool occupants in adjacent subzones shaded from the sun (Arens et al. 2015; Marino et al. 2017), and increases in the MRT and changed thermal perception of the occupants.

As shown in previous publications (Arens et al., 2015; Marino et al., 2017) shortwave incoming radiation can be the most influential component driving human comfort close to the façade. Direct solar radiation on an occupant causes a substantial MRT increase may be beyond the HVAC system's capacity to address.

Several surveys have highlighted (Konis, 2013; Konis and Selkowitz, 2017) that in many buildings characterized by a high WWR, the daylit perimeter area is often unoccupied or the occupants are forced to deploy the shading for most of the day because of intolerable thermal conditions created by excess incoming solar radiation. In addition to the direct effect on occupants' well-being and productivity (Akimoto et al., 2010; Huizenga et al., 2006; Frontczak et al., 2012), this phenomenon has profound impacts on daylight, energy building performance (Bessoudo et al, 2010; Marino et al., 2017), and economic efficiency because of the unused floor area near windows. Due to a lack of methods and standards, for many years sustainable designers and architects focused more on visual discomfort (Jakubiec and Reinhart, 2012; Nabil and Mardaljevic, 2005; Konstantzos and Tzempelikos, 2014) and radiant temperature asymmetry (Bessoudo et al., 2010; Mackey et al., 2017); but did not grapple with the discomfort implications of solar radiation landing directly on the body.

Only recently did ASHRAE standard 55-2017, through Appendix C, adopt two approaches to assess discomfort for occupants exposed to shortwave radiation:

1. Prescriptive approach: assume an MRT equal to 2.8 ${ }^{\circ} \mathrm{C}$ above the average air temperature. This method can be applied only when the design meets prescribed conditions such as glazing elements' Uvalue, maximum window size, maximum solar heat gain coefficient, blind solar transmission, and minimum distance from the facade.

2. Performance approach based on the work of Arens (Arens et al., 2015) for the full calculation of MRT: first compute the longwave and shortwave MRT and then sum the two quantities in order to obtain the adjusted MRT. As explained in the standard, the shortwave MRT is a function of the context, solar transmittance of the fenestration system, occupant position and posture, body exposure, sun position and irradiance value and clothing absorptivity.

The ASHRAE full calculation method is currently implemented in different tools such as the SolarCal module of the CBE Thermal Comfort Tool (Hoyt et al., 2017) and Ladybug Comfort Component (MenchacaBrandan et al., 2017; Roudsari et al., 2013). Recently, to overcome limitations in the tools mentioned above, (point-in-time evaluation, arbitrary selection of representative occupant, and simplifications to the occupant's exposure to sky vault and to direct sun in complex furniture and fenestration configurations), a new workflow based on Radiance and EnergyPlus has been developed by Zani et al (2018).

The new method uses Radiance to assess the hourly intensity of solar radiation that passes through a façade 
and lands on the human body combined with EnergyPlus to calculate the longwave MRT.

Currently, many research projects on daylight visual (Giovannini et al. 2018; Jakubiec, 2018) and thermal comfort (Mackey et al. 2017) attempt to develop and define new simulation frameworks to extend the results from a single position to the entire space in order to achieve a better understanding of whole building performance.

With the same aim, in this paper, we present a new simulation framework, based on Zani's paper (2018) and ASHRAE 55-17 appendix C. The framework predicts the variation in indoor thermal comfort of occupants exposed to solar radiation across the floor plan by computing the change in MRT as a function of the amount of the body's exposed area and of the intensity of direct solar radiation. We present the results introducing a new metric called Annual Radiation Discomfort (ARD) index that describes the number of hours during the year that potential discomfort is caused by solar radiation, and the intensity of the thermal discomfort, in terms of delta Mean Radiant Temperature $(\triangle \mathrm{MRT})$.

In the first part of this paper, we illustrate the main assumptions and characteristics of the simulation framework. In the second part, we apply the framework and the metric to a façade optimization case study with the goal of reducing the number and intensity of discomfort hours due to solar radiation while maintaining a high level of usable daylight. Finally, given that in architectural practice, facades and floor plan design choices are often driven by daylight analyses using metrics such as Useful Daylight Illuminance (UDI) (Reinhart and Walkenhorst, 2001) and Annual Sunlight Exposure (ASE), we compare the ARD metric to daylight metrics in order to capture possible similarities. In addition, hourly $\triangle \mathrm{MRT}$ values are compared to illuminance values to determine whether reasonable horizontal illuminance thresholds exist that can express the influence of solar radiation on thermal comfort.

\section{Methods}

To calculate the MRT for an occupant in a space, we used the methodology defined by Zani (2018). Radiance is used to calculate the radiation on a simplified manikin located in the space for every hour of the year. The total radiation on the manikin is then used to calculate the $\triangle \mathrm{MRT}$. The $\triangle \mathrm{MRT}$ for each location throughout the space is then translated into ARD by determining the number of occupied hours in which the $\triangle \mathrm{MRT}$ exceeds the acceptable threshold. A detailed descript of each step is included below.

\section{Mean Radiant Temperature}

The method established by Zani was used to simulate the change in MRT due to solar radiation. Only the relevant parts used to simulate the total radiation falling on a body and calculate $\triangle \mathrm{MRT}$ were used for this framework. The following workflow is used to calculate $\triangle \mathrm{MRT}$ :

1. A complete space, including exterior obstructions and interior spatial conditions, is modelled in Rhinoceros, a 3d modelling software.
Using Grasshopper, a visual programming plugin for Rhinoceros, simplified manikins are placed throughout the space. Zani had used a highresolution manikin in previously establishing the methodology; this was shown to faithfully reproduce the performance results given in ASHRAE standard 55-2017 Appendix C. The complex manikin required substantial computational resources resulting in increased simulation times and model complexity, so to ensure that the methodology proposed in this paper could be used across multiple locations within a complex space, a low-resolution manikin was developed. The high-resolution model had 232 mesh faces, whereas the proposed lowresolution model has only 28 ( $88 \%$ reduction). The difference in the two models is seen in Figure 1. To ensure that the manikin simplification did not result in significant error, a detailed study was undertaken of the $\triangle \mathrm{MRT}$ results from both manikins deployed in the standard ASHRAE BESTEST office space with a range external shading. The results in Figure 2 show that the mean absolute error (MAE) remains above 0.90 under multiple façade and environmental conditions. Furthermore, the simulation time required decreased by up to $90 \%$. In particular, in the range of $\triangle \mathrm{MRT}$ between 2 and $5{ }^{\circ} \mathrm{C}$ that represents the tolerable range in the thermal comfort zone, the accuracy remains high with a MAE of less than half a degree. A visual inspection of the data and the residuals shows that the linear model assumptions are satisfied for the case with no shade and with medium density shade. This significant decrease in simulation time and negligible error made us confident that the simplified approach was appropriate. In the following tests of the framework the LR manikin is used exclusively on architectural examples that are typical but involving relatively simple glazing and medium-density shading configurations.

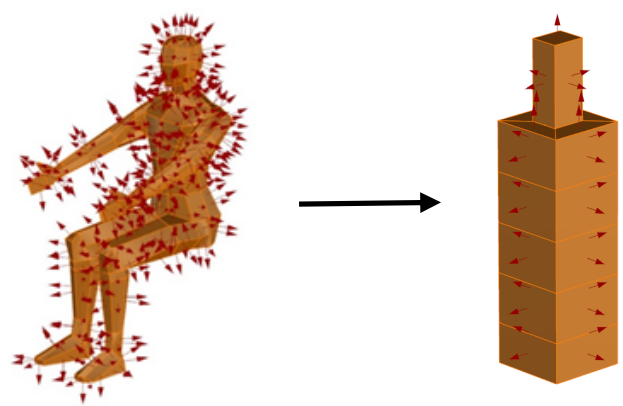

Figure 1: Manikin geometrical and analytical simplification.

2. Using Honeybee, a plugin for Grasshopper that provides an interface for Radiance, material properties can be assigned to the model of a space that has been imported into Grasshopper. Material properties including, solar transmittance, surface reflectances, and complex fenestration assemblies can be modelled. The Radiance simulation parameters appropriate for the simulated space can 
also be set before the entire model is exported to Radiance for simulating the radiation falling on the manikin.
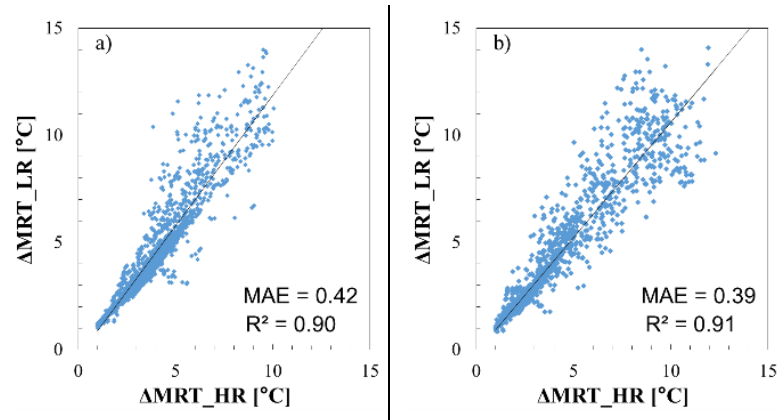

Figure 2: Accuracy comparison between high and lowresolution manikins for two facade configuration no shading (a), louvers (b).

3. Once exported to Radiance, the radiation falling on the manikin can be simulated. Using reverse ray tracing, Radiance calculates the rate of hourly radiation falling on each center point of the manikin mesh faces. Radiance produces an illuminance file output that consists of the rate of radiation in $\mathrm{W} / \mathrm{m}^{2}$ at each point for each hour of the year.

4. The illuminance file is processed using a simple Python script. The script reads the radiation rate falling on each point and multiplies it by the area of the corresponding mesh face to determine the total radiation falling on the surface. This is then totalled for each manikin to determine the total radiation falling on the body in each hour of the year. To calculate hourly ERF and $\triangle \mathrm{MRT}$ for each manikin, we used the formulas described in (Arens et al., 2015). To create visualizations, the Python code then writes a comma-separated value file with the hourly results for each manikin.

This simulation framework allows a designer to quickly and effectively calculate the $\triangle \mathrm{MRT}$ of an occupant in multiple locations throughout a space at multiple times throughout the year.

\section{Calculation of Annual Radiation Discomfort (ARD)}

Broadly, the Annual Discomfort Radiation (ARD) metric can be described as the percentage of occupied hours that are above the acceptable $\triangle \mathrm{MRT}$ range. The ADR metric is based on a metric like Daylight Autonomy (DA) that coveys the percentage of time a condition is met (Carlucci, Causone, De Rosa, \& Pagliano, 2015). The ADR index is defined as the percentage of the occupied hours (from 8 to 18) throughout the year when the $\Delta \mathrm{MRT}$ for each manikin position is over a threshold of $4{ }^{\circ} \mathrm{C}$ as shown in the formula below.

$$
A R D=\frac{\Sigma_{j}\left(w f_{i} \cdot \mathrm{t}_{i}\right)}{\Sigma_{j} \mathrm{t}_{i}} \quad 8 a m<\mathrm{t}_{i}<6 p m
$$

with $w f_{i}=1$ if $\Delta \mathrm{MRT}>4^{\circ} \mathrm{C}$ or $w f_{i}=0$ if $\Delta \mathrm{MRT}<4^{\circ} \mathrm{C}$

Where the $t_{i}$ is each occupied hour in a year; and the $\triangle \mathrm{MRT}_{\mathrm{i}}$ is the hourly value of shortwave mean radiant temperature for each point of the grid.

A threshold of $4^{\circ} \mathrm{C} \triangle \mathrm{MRT}$ was selected for the ARD metric because, starting from a neutral thermal condition with a PMV value between -0.1 and 0.1 , a MRT increase of this magnitude produces a shift in an occupant's comfort zone that moves the occupant outside the acceptable boundaries, causing slightly warm conditions (see Figure 3). Underlying the definition of the ARD index is the assumption that the overall space, and in particular the area close to the façade, is properly thermally controlled by the HVAC system. Specifically, the HVAC system is able to maintain the comfort conditions of occupants when the sun is not striking the space. The actual definition has not been evaluated for other comfort methods such as the adaptive method (de Dear and Brager, 1998). Given the variability in the thermal comfort range based on façade configuration, space activities space subdivision, and effectiveness of mechanical systems, the $\Delta$ MRT threshold can be adjusted on a case by case basis. By deliberately only using $\triangle \mathrm{MRT}$ in the calculation of the ARD metric, the results are decoupled from the HVAC system. This allows designers to isolate the effect of direct solar radiation on the comfort of occupants across the spaces they design, providing specific insight that was unavailable before.

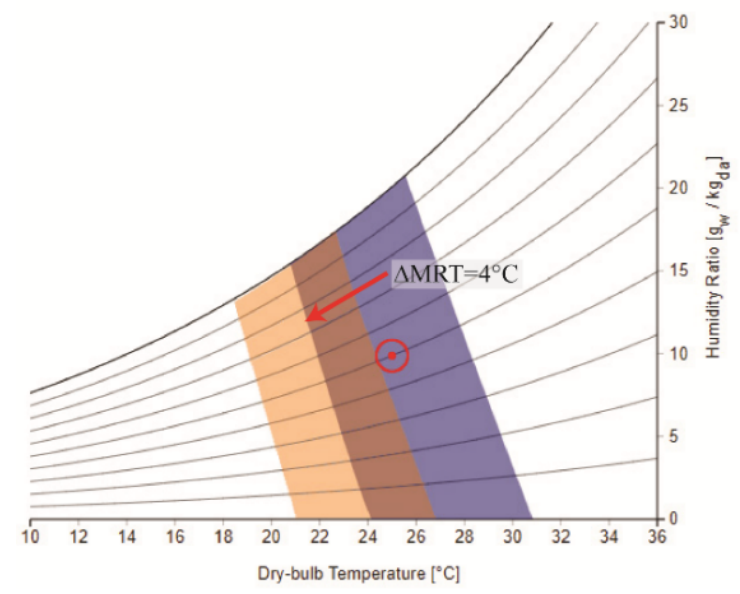

Figure 3: Comfort zone shift due to the increment of MRT caused by incoming solar radiation.

To calculate the ARD for a space, a Python script was developed to process the previously produced $\triangle \mathrm{MRT}$ using the formula described above. This script evaluates each location of a manikin for the percentage of hours that exceeds the acceptable threshold and records it to a .csv output. This output can then be loaded back into Grasshopper for color scale visualizations or assess to determine percentile assessments as shown in Figure 4.

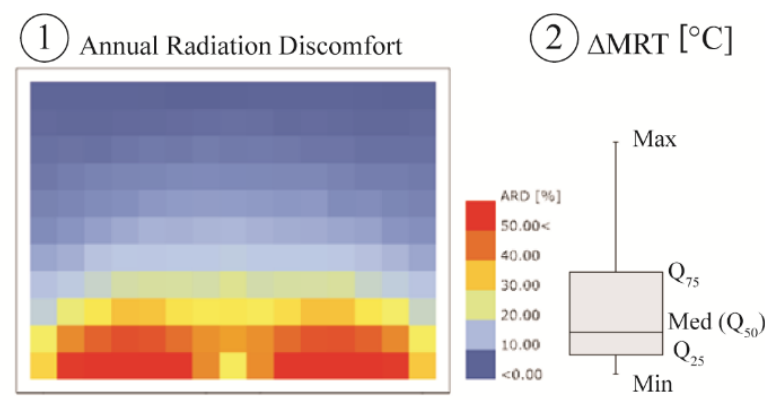

Figure 4: Framework results: ARD spatial color map (left) and $\triangle M R T$ intensity distribution (right). 


\section{Case study description and simulation method}

Following the preliminary test presented in the previous section and in (Zani et al., 2018), we applied the new metric presented in the previous section to the design workflow for an airport renovation in New York City $\left(40.71^{\circ} \mathrm{N}, 74.00^{\circ} \mathrm{W}\right)$. The airport terminal concourse consists of a double height open space 30 meters wide and 200 meters long divided into two sitting areas and one central transit area. The area is sidelit from two fully glazed curtain walls 5 meters high and two clerestory windows facing south-east and north-west as shown in the section and plan in Figure 5.

The facade configurations investigated consist of a baseline glazing build-up (solar transmission 0.49) with different solar shading systems applied. As summarized in table 1 , we tested 4 different configurations for the south facing facade and one option for the north facing.
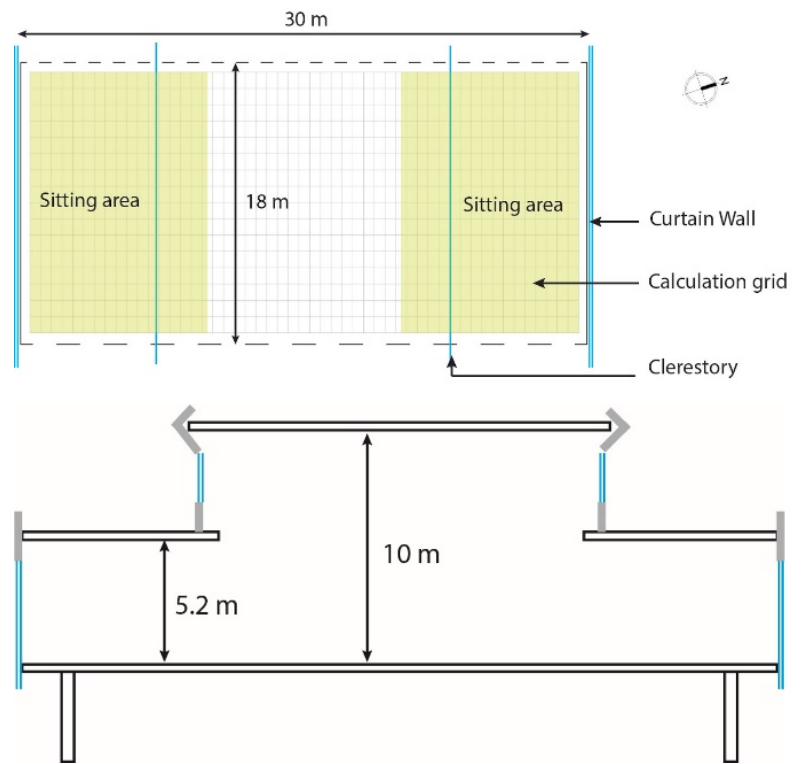

Figure 5: Plan and section view - concourse area.

The baseline is characterized by a fully glazed curtain wall without an external screen. We have simulated two additional shading systems consisting of 1.5 meter overhang and $25 \mathrm{~cm}$ wide louvers. In the fourth options, in order to reduce the WWR without modifying the visual appearance, we introduced a 1 meter high shadowbox coupled with external louvers.

Additionally, in order to show the influence of the coating selection to the design team, we simulated a solar control glazing with a solar transmittance of 0.36 . No internal operable shading, such as venetian blinds or roller shades, have been considered given the high installation and maintenance costs of a fully automated system and lack of regular visitors. In addition to the typical daylight (75\% sDA and 10\% ASE) and thermal comfort (ASHRAE Standard 55-2010) standards used by LEED V4, we evaluated the facade performance following the guidelines included in ASHRAE 55-2017 appendix C in order to minimize the effect of incoming shortwave radiation on the mean radiant temperature experienced by the occupants. Given the high WWR and limitations in glass selection (highly neutral color coating) set by the architects, the final objective of the study was to define an external solar shading solution that was capable of the greatest reductions in magnitude of discomfort in the space and number of hours of discomfort near the facade. Moreover, we investigated the correlation between ARD and illuminance-based metrics such as UDI and ASE, using a fault detection approach and comparing the spatial distribution over a typical section of the airport.

Table 1: Facade configurations and material definition.

\begin{tabular}{|c|c|c|c|}
\hline Facade type & Code & $\begin{array}{c}\text { Glazing } \\
\text { (VLT/Tsol) }\end{array}$ & $\begin{array}{c}\text { Shading } \\
\text { (refl) }\end{array}$ \\
\hline No shading (Baseline) & B & $0.81 / 0.49$ & - \\
\hline Overhang & O & $0.81 / 0.49$ & 0.20 \\
\hline Louvers & L & $0.81 / 0.49$ & 0.20 \\
\hline Louvers+Shadowbox & L-S & $0.81 / 0.49$ & 0.20 \\
\hline $\begin{array}{c}\text { Vertical fins - North } \\
\text { facade }\end{array}$ & - & $0.81 / 0.49$ & 0.20 \\
\hline $\begin{array}{c}\text { Solar Control Glazing } \\
\text { - (No shading) }\end{array}$ & SCG & $0.72 / 0.36$ & - \\
\hline
\end{tabular}

\section{Results}

Figure 6 and 7 show respectively the ARD profile across the space and the box-plot visualization of $\triangle \mathrm{MRT}$ range for the five cases analyzed. In the baseline case with a typical Low-E glass (B), the number of uncomfortable hours due to incoming solar radiation falling on the occupants reaches peaks of $50-60 \%$ in the first two meters and around $30-40 \%$ in the following two meters. An acceptable threshold of $10 \%$ (Carlucci, Pagliano, and Sangalli, 2014) is reached after 6 meters. At the northwest facade, only in the first meter is ARD over $10 \%$. As shown in the box-plot representation, fig. 7, for the baseline, the median value in the first four meters is 3.2 ${ }^{\circ} \mathrm{C}$; close to the critical threshold of $4{ }^{\circ} \mathrm{C}$. In addition, we note a wide variation in the third and upper quartiles, with a peak of $14^{\circ} \mathrm{C}$.

The introduction of $0.2 \mathrm{~m}$ wide vertical louvers on the north-west facade, was able to guarantee comfortable space close to the facade for the entire year.

For the south façade, by adding external solar shading such as Overhang $(\mathrm{O})$ and Louvers $(\mathrm{L})$, we were able to reduce the number of uncomfortable hours near the façade by $15 \%$ in the first meter and by $25 \%$ in the second meter. We achieved a consistent reduction also in the third quartile and median values of $\triangle \mathrm{MRT}$. In addition, the boxplot shows that $75 \%$ of $\triangle \mathrm{MRT}$ values are below the critical threshold of $4{ }^{\circ} \mathrm{C}$.

Finally, coupling a shadowbox with the external louvers (L-S), we achieved a further improvement in the control of incoming shortwave with an average value of ARD in the first three meters equal to $10 \%$ and a peak of $13 \%$ in the first meter. The overall improvement can be visualized also in the box-plot, with a significant reduction in the 


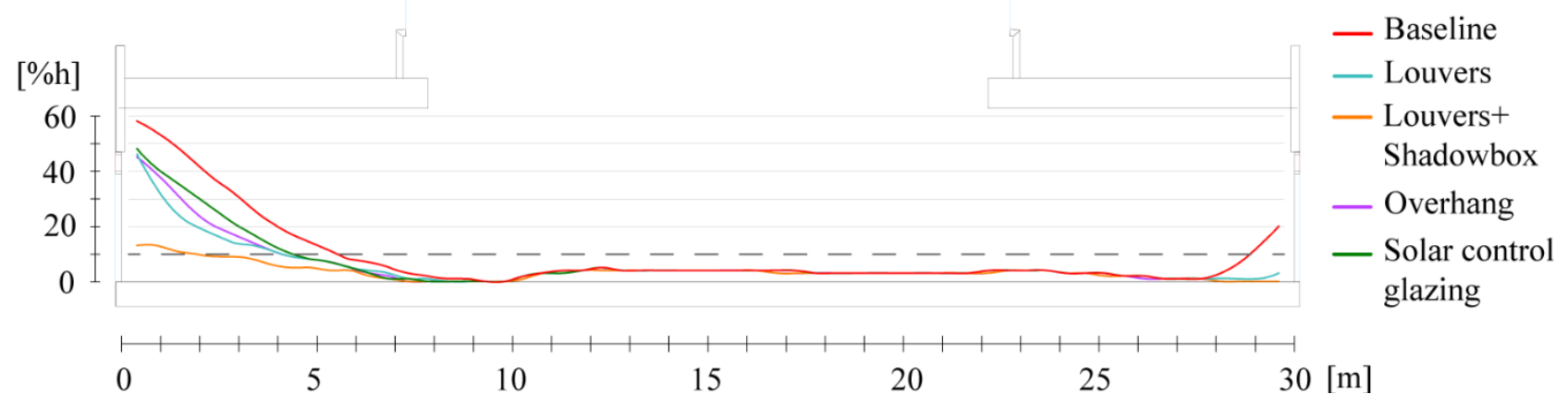

Figure 6: ARD profile across a typical section of the airport waiting area.

peak value $\left(9^{\circ} \mathrm{C}\right)$ and limited variation between the median $\left(1.2^{\circ} \mathrm{C}\right)$ and the third quartile.

In addition to ARD results, the space was assessed for daylight performance. Table 2 shows for the same cases presented for ARD, the overall daylight performance. Considering the three metrics, we can understand that the louvers+shadowbox configuration (L-S) presents the best daylight performance with the highest level of UDI and the lowest ASE compared to the other solutions, while at the same time maintaining similar levels of spatial Daylight Autonomy (sDA).

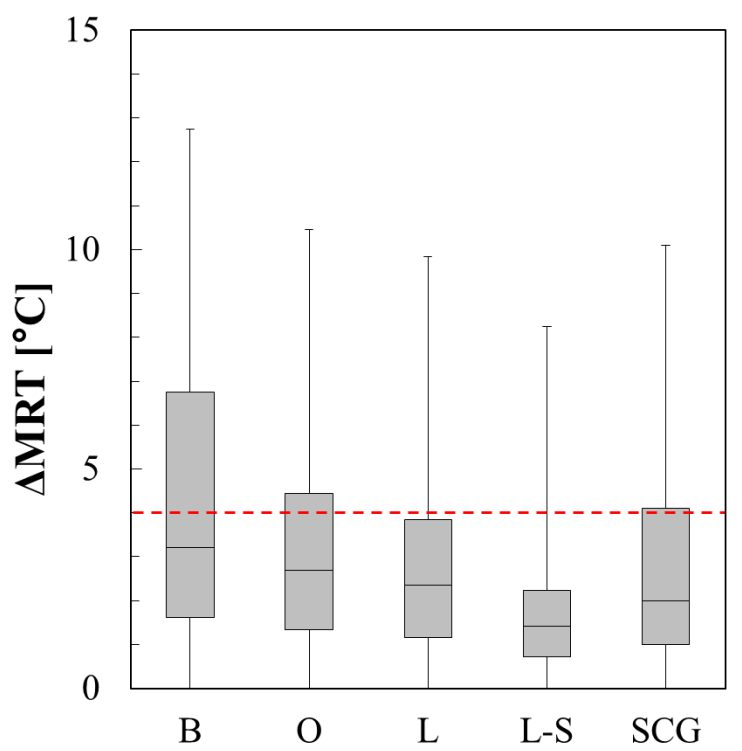

Figure 7: $\triangle M R T$ distribution over the year in the first 4 $m$ from the facade for different facade layout.

Taking into account both "thermal" and daylight performance, the façade configuration with reduced WWR and shading system performs better by decreasing the number of uncomfortable hours near the glazing and eliminating potential unusable seating space due to the uncomfortable increases in MRT.

\section{Comparison between Annual Radiation Discomfort and Illuminance metrics}

The daylight results were also assessed to determine a threshold for horizontal illuminance that could be used as a proxy for $\triangle \mathrm{MRT}$. The most suitable values of horizontal illuminance (Eh) values to be used as a threshold to assess thermal discomfort from solar radiation were found through the application of a fault-detection technique. We applied the fault-detection technique to the simulation points within the first six meters from the facade for three different cases: baseline, louvers, and solar control glazing.

Table 2: Daylight performance scores.

\begin{tabular}{|c|c|c|c|c|}
\hline & $\begin{array}{c}\text { sDA } \\
{[\%]}\end{array}$ & $\begin{array}{c}\text { UDI } \\
{[\%]}\end{array}$ & $\begin{array}{c}\text { UDI>3000 } \\
{[\%]}\end{array}$ & $\begin{array}{c}\text { ASE } \\
{[\%]}\end{array}$ \\
\hline Baseline (B) & 91.3 & 73.1 & 20.8 & 21.6 \\
\hline Overhang (O) & 91 & 78.4 & 14.9 & 18.3 \\
\hline Louvers (L) & 90.7 & 79.3 & 13.8 & 15 \\
\hline $\begin{array}{c}\text { Louvers+Shadow } \\
\text { box (L-S) }\end{array}$ & 89.7 & 86.9 & 5.2 & 9.6 \\
\hline $\begin{array}{c}\text { Solar Control } \\
\text { Glass (SCG) }\end{array}$ & 90.7 & 79.5 & 13.5 & 21.3 \\
\hline
\end{tabular}

This analysis identified an illuminance threshold suitable for estimating the $\triangle \mathrm{MRT}$ calculation output. As shown in the scatter plot graphs in fig. 8, replacing the $\triangle \mathrm{MRT}$ calculation with illuminance threshold allows designers to identify the potential discomfort and the frequency, but not the actual magnitude. Table 3 summarizes the error, for each of the three cases, when evaluating the $\triangle \mathrm{MRT}$ using an illuminance threshold of 4000 and 5000 lux. The error is expressed in terms of False Positive + False Negative percentage, representing the percentage of hours during year within the first six meters from the facade in which the $4{ }^{\circ} \mathrm{C} \triangle \mathrm{MRT}$ threshold is overestimated (FP) or underestimated (FN) by using the illuminance threshold. Both thresholds for all the cases present a total error less than $10 \%$, close to the threshold defined in the EN 15251. 4000 Lux threshold gives a lower error for the louvered facade configuration, but the 5000 lux threshold more accurately estimates the baseline and solar control glass cases. Considering the overall error trend, we recommend a threshold of 5000 lux for a spatial distribution comparison if using this approach. 

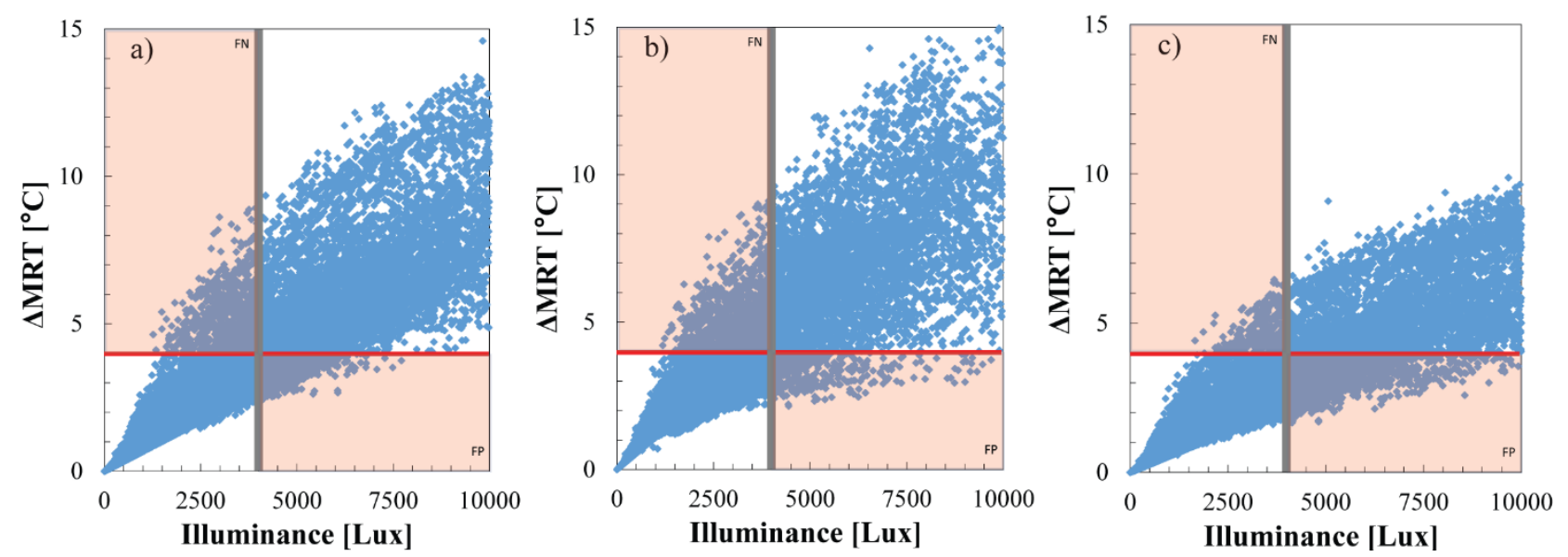

Figure 8: $\triangle M R T$ vs. Illuminance value through fault detection technique for three different facade configurations in the first $6 \mathrm{~m}$ from the facade. No Shading (a), Louvers (b), Solar control glass (c).

Table 3: Error made when evaluating $\triangle M R T$ using illuminance threshold for different facade configurations in the first $6 \mathrm{~m}$ from the facade. The errors are expressed as $F P+F N$ percentage.

\begin{tabular}{|c|c|c|c|}
\hline & Baseline & Louvers & $\begin{array}{c}\text { Solar control } \\
\text { glass }\end{array}$ \\
\hline Thr 4000 lux & $8 \%$ & $5 \%$ & $8 \%$ \\
\hline Thr 5000 lux & $6 \%$ & $8 \%$ & $4 \%$ \\
\hline
\end{tabular}

Finally, we investigated the spatial distribution between ARD, UDI $>5000$ and ASE. Fig. 9 shows that UDI over 5000 lux and ARD present a similar spatial distribution of potential discomfort hours for both cases (Baseline and Solar control glazing) across the entire floor plan. On the south facade, it is possible to notice that UDI overestimates the amount of discomfort of hours close to the facade, but it decreases more rapidly in comparison to ARD. The magnitude and falloff of UDI is greater than that of ARD. For instance, the area of the baseline exceeding the $50 \%$ threshold only extends $2 \mathrm{~m}$ for ARD while it extends up to $3 \mathrm{~m}$ for UDI $>5000$. Conversely, ARD exceeds $10 \%$ up to 7 meters into the space while UDI $>5000$ greater than $10 \%$ stops near $6 \mathrm{~m}$ deep into the space.

The Annual Sunlight Exposure (ASE) metric is able to identify potential areas of discomfort (indicated in dark purple) but does not provide clear information about the actual number of discomfort hours. The distribution of ASE hours (color shading) has a similar trend to ARD for the $10 \%$ threshold. In addition, it appears that complying with the ASE threshold of $10 \%$ stated in LEED V4 is sufficient to ensure that the space will be thermally comfortable because of the strictness of the metric.

\section{Discussion}

The case study shows the effectiveness of the ARD metric in the design process by identifying which strategies are most effective at creating spaces without discomfort caused by the sun impacting occupants. In this particular design case, vertical louvers on the north façade and a reduced WWR with horizontal louvers over the remaining glazing on the south façade were effective at reducing incoming solar radiation and improving comfort conditions. The use of the ARD metric helped to easily identify the best strategies. The results showed an improvement of about $130 \%$ compared to the baseline configurations, while at the same time enabling welldaylit spaces where sDA exceeded $85 \%$.

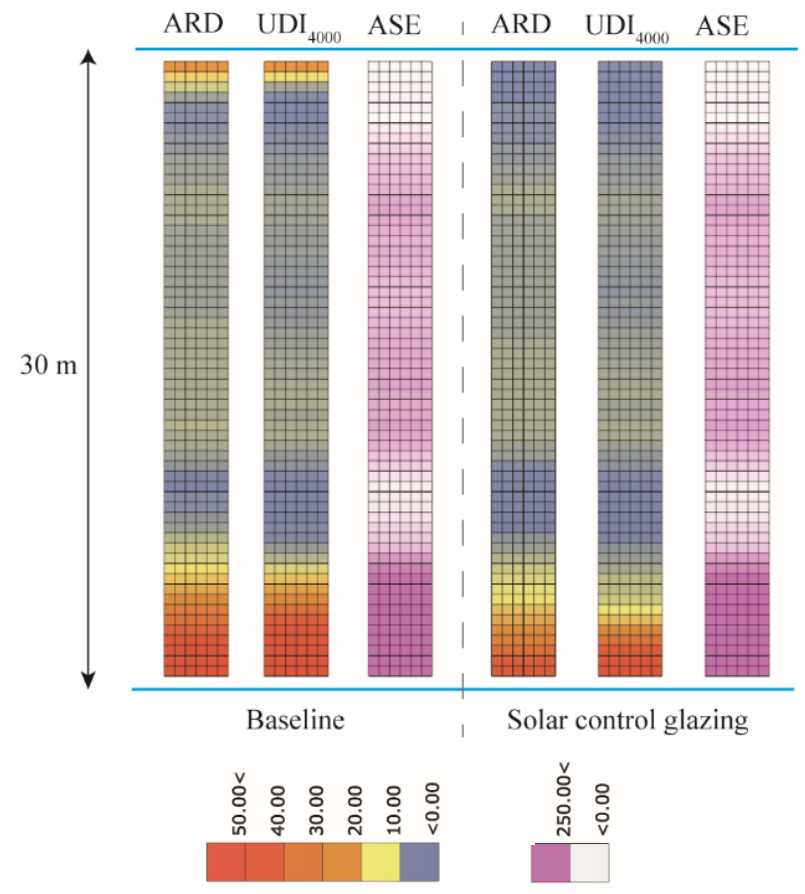

Figure 9: False color spatial comparison between ARD, UDI5000, ASE.

The comparison of the case study ARD results with daylight metrics showed that while the daylight metrics are indicative of thermal comfort performance, they diverge in details in both magnitude and distribution. The UDI $>5000$ metric provides useful insight, but compresses the affected area when compared to ARD. Because the ASE has a hard 250 hours compliance threshold, it does not fully capture the variation in direct sunlight across the floor. When the ASE metric shows compliance with the 
LEED standard, thermal discomfort caused by direct sunlight is not likely to be a problem due to the strictness of the ASE metric. However, if the ASE metric does not show compliance, there is not enough granularity to provide insight into how potential discomfort might be distributed across the space.

While daylighting metrics can be considered indicative of thermal comfort performance, metrics like $\triangle \mathrm{MRT}$ and ARD should be used in cases specifically looking at thermal performance.

This case study shows the flexibility of the ARD metric in the design process and how it can be applied to many design conditions.

\section{Conclusion}

The paper presents a new framework and metric to assess the influence of solar radiation on thermal comfort across the floor plate and includes a preliminary comparison between ARD and daylight metrics based on a case study. The case study results show that the integration of the new framework into the design process, in addition to classic daylight metrics, can help designers optimize façade systems and propose effective strategies that reduce thermal discomfort hours.

Because the ARD metric is unmoored from mechanical considerations, it shows the isolated effect of facade on comfort due to direct sun. Thus, it can be used in the design process to further refine glazed facades to optimize for comfort as well as usable daylight and reduce unused space near the façade caused by increased temperatures. This adds a new tool for environmental designers to communicate the impacts of design decisions and focuses the conversation on comfort as well as the other daylight and heat control considerations that are typically considered.

Fundamentally, as shown in the comparison of ARD with the daylighting metrics, the appearance of direct sunlight on a floor plate indicates that discomfort might occur. While existing daylight metrics can be used to approximate if and where solar discomfort may occur, they do not fully capture the complexity and duration of the potential solar discomfort shown through the ARD metric. The ARD metric provides particular insight into potential discomfort caused by direct sunlight and provides insight that can be used by designers to propose design solutions to address it.

The new framework was tested on a limited number of cases and therefore, future studies will focus on more extensive testing of façade and space configurations. Additionally, integrating the tool and python script directly into grasshopper will ease the use of $\triangle \mathrm{MRT}$ and the ARD metric in the design process.

\section{Acknowledgement}

We thank all the people that provided helpful comments on previous versions of this document. A special thanks to Andrea G. Mainini and Juan Blanco Cadena for the support during the preliminary tests of the workflow.

\section{References}

Akimoto, T., Tanabe, S. ichi, Yanai, T., \& Sasaki, M.
(2010). Thermal comfort and productivity Evaluation of workplace environment in a task conditioned office. Building and Environment, 45(1), 45-50.

Alejandra Menchaca-Brandan, M., Baranova, V., Petermann, L., Koltun, S., \& Mackey, C. (2017). Glazing and Winter Comfort Part 1: An Accessible Web Tool for Early Design Decision-Making, 2326-2333.

Arens, E., Hoyt, T., Zhou, X., Huang, L., Zhang, H., \& Schiavon, S. (2015). Modeling the comfort effects of short-wave solar radiation indoors. Building and Environment, 88, 3-9.

Bessoudo, M., Tzempelikos, a., Athienitis, a. K., \& Zmeureanu, R. (2010). Indoor thermal environmental conditions near glazed facades with shading devices - Part I: Experiments and building thermal model. Building and Environment, 45(11), 2506-2516.

Carlucci, S., Causone, F., De Rosa, F., \& Pagliano, L. (2015). A review of indices for assessing visual comfort with a view to their use in optimization processes to support building integrated design. Renewable and Sustainable Energy Reviews, 47(7491), 1016-1033.

Carlucci, S., Pagliano, L., \& Sangalli, A. (2014). Statistical analysis of the ranking capability of longterm thermal discomfort indices and their adoption in optimization processes to support building design. Building and Environment, 75, 114-131.

Christopher Mackey, Vera Baranova, Lynn Petermann, M. A. M.-B. (2017). Glazing and Winter Comfort Part 2: An Advanced Tool for Complex Spatial and Temporal Conditions (pp. 2317-2325).

Dear, R. J. De, Brager, G. S., Reardon, J., Nicol, F., \& Ph, D. (1998). Developing an Adaptive Model of Thermal Comfort and Preference. The American Society of Heating, Refrigerating and Air Conditioning Engineers, Inc., and Macquarie Research, Ltd, 4106(March).

Giovannini, L., Favoino, F., Lo Verso, V., Pellegrino, A., \& Serra, V. (2018). A Simplified Approach for the Annual and Spatial Evaluation of the Comfort Classes of Daylight Glare Using Vertical Illuminances. Buildings, 8(12), 171.

Hoyt T., Schiavon S., Piccioli A., Cheung T., Moon D., S. K. (2017). CBE Thermal Comfort Tool. Retrieved from http://comfort.cbe.berkeley.edu/

Huizenga, C., Abbaszadeh, S., Zagreus, L., \& Arens, E. (2006). Air quality and thermal comfort in office buildings : Results of a large indoor environmental quality survey. Proceedings of Healthy Buildings, III, 393-397. https://doi.org/10.12659/PJR.894050

Jakubiec, J. A. (2018). Validation of Simplified Visual Discomfort Calculations. Building Simulation and Optimization Conference (BSO2018), (September), 11-12. 
Jakubiec, J., \& Reinhart, C. (2012). The "adaptive zone" - A concept for assessing discomfort glare throughout daylit spaces. Lighting Research \& Technology, 44(2), 149-170.

Konis, K. (2013). Evaluating daylighting effectiveness and occupant visual comfort in a side-lit open-plan office building in San Francisco, California. Building and Environment, 59(January 2013), 662677.

Konis, K., \& Selkowitz, S. (2017). Effective Daylighting with High-Performance Facades. (Springer, Ed.).

Konstantzos, I., \& Tzempelikos, A. (2014). Daylight Glare Probability Measurements And Correlation With Indoor Illuminances In A Full- Scale Office With Dynamic Shading Controls. International High Performance Buildings Conference, 147.

Marino, C., Nucara, A., \& Pietrafesa, M. (2017). Thermal comfort in indoor environment: Effect of the solar radiation on the radiant temperature asymmetry. Solar Energy, 144, 295-309.

Marino, C., Nucara, A., Pietrafesa, M., \& Polimeni, E. (2017). The effect of the short wave radiation and its reflected components on the mean radiant temperature: modelling and preliminary experimental results. Journal of Building Engineering, 9 (November 2016), 42-51.

Mostapha Sadeghipour Roudsari, Michelle Pak, Smith, A. (2013). Ladybug: a Parametric Environmental Plugin for Grasshopper To Help Designers Create an Environmentally-Conscious Design. 13th Conference of International Building Performance Simulation Association, 3129-3135.

Nabil, A., Mardaljevic J., (2005). Useful Daylight Illuminance: A new paradigm for assessing daylight in buildings. Lighting Research and Technology, 41-59.

Reinhart, C. F., \& Walkenhorst, O. (2001). Validation of dynamic RADIANCE-based daylight simulations for a test office with external blinds. Energy and Buildings, 33(7), 683-697.

Zani, A., Mainini, A. G., Cadena, J. D. B., Schiavon, S., \& Arens, E. (2018). A New Modeling Approach for the Assessment of the Effect of Solar Radiation on Indoor Thermal Comfort. Building Performance Analysis Conference and SimBuild. 